Indian J. Anim. HIth. (2019), 58(2) -Special Issue: 87-104

DOI: https://doi.org/10.36062/ijah.58.2SPL.2019.87-104

\title{
ANTIBIOTIC RESIDUES IN MEAT PRODUCTS AND PUBLIC HEALTH IMPORTANCE IN THE PERSPECTIVE OF DRUG RESISTANCE
}

\author{
S. BISWAS, R. BANERJEE, ARUN. K. DAS ${ }^{* 1}$, M. MUTHUKUMAR ${ }^{2}$, \\ B. M. NAVEENA ${ }^{2}$, O. BISWAS ${ }^{3}$ AND G. PATRA \\ Department of Livestock Products Technology \\ F/o Veterinary and Animal Sciences \\ West Bengal University of Animal \& Fishery Sciences \\ 37, K.B. Sarani, Kolkata-700 037, West Bengal, India
}

\begin{abstract}
While rearing food animals, the use of antibiotics is inevitable and this often generates potential threat to consumer health by developing residues in animal products. Such use of antibiotics should strictly be regulated in doses and duration as indiscriminate use is link to antimicrobial resistance (AMR). The rising concern of AMR has prompted the regional and global authorities to develop the guidelines and policies concerning judicious use of antibiotics and containment of AMR. However, such initiatives in developing countries like India where high occurrence of antibiotic-resistant bacteria in animals reared for food purpose is still in a nascent stage. The purpose of this writeup is to consider the emerging adverse health effects of antibiotic residues in humans and animals along with to introspect the issues relating to the development of antibiotic resistance, existing global and national policies on antibiotics use, its strategies and further recommendations for judicious use of antibiotics in food animals.
\end{abstract}

Key words: Antibiotic residues, Antimicrobial resistance, Health effects, Policies, Recommendations

Antimicrobial resistance (AMR) is a major threat worldwide and more important in developing countries including in India where it is considered as emergence due to the burden of various infectious diseases, use of antibiotics and resulting occurrence of antimicrobial resistance (Laxminarayan et al., 2013, 2016). AMR along is becoming the reason of making victims of people more than the total victims of cancer and road accidents, and it is alarming that by 2050 this figures will be much more than 10 million than that of the present figure of 700,000 people losing the battle to AMR per year (O'Neill, 2016). While projecting disaster effect of AMR on economic point of view, it is suggested that AMR could alone diminish $2-3.5 \%$ of gross domestic product (GDP) equating a total value of USD100 trillion to the world (O'Neill, 2014). Indiscriminate in the form of overuse and misuse of antibiotics or other antimicrobial agents are the main contributing factor for the development of such high rates of

*Corresponding Author

${ }^{1}$ Eastern Regional Station, ICAR-Indian Veterinary Research Institute, Kolkata 700037

${ }^{2}$ ICAR-National Research Centre on Meat, Chengicherla, Hyderabad - 92

${ }^{3}$ Department of Agricultural Engineering, Visva-Bharati, Sriniketan-731 236 
resistance (WHO, 2014).The public health researchers all over the world have termed these resistant microorganisms as 'nightmare bacteria' that often called 'pose a catastrophic threat' to human beings.

There is an increased demand for animal products in India which is related to rising incomes and growing population. Therefore, in order to stay competitive, producers mainly rely on antibiotics and other antimicrobial agents to promote growth, prevent the spread of diseases and treat sick animals. The issue of antibiotic resistance becomes more pronounced and concerned due to the fact that most of the commonly used antibiotics in animals are the same that are used for the treatment of human beings. This has raised concerns about reducing the effectiveness of such antibiotics when used for treating human infections.

It has been reported that antibiotic consumption in 71 countries increased by $36 \%$ between 2000 and 2010 with Brazil, Russia, India, China, and South Africa (BRICS) which account for three-quarters of this increase (Van Boeckel et al., 2015). The use of antibiotics and other antimicrobial agents in chickens, in particular, is expected to increase by triple in India by 2030 . Increasing and indiscriminate in the form of overuse and misuse of antibiotics or other antimicrobial agents is considered as main factor for increase in antibiotic resistance, in both humans and animals. Resistant bacteria or microorganisms could be transmitted between humans and animals through various routes such as contact, food products, and the environment. It has been also reported that antibiotic residues, as well as resistant microorganisms, have been found in live animals in India as well as in related animal food products and in many cases, within the same community, the same strains of resistant bacteria are also detected in human and environmental sources. The global rise of AMR has attracted the attention of World Health Organization (WHO) and several other stakeholders. India has also framed its National Action Plan (NAP) for AMR (GOI, 2017). As it is a multi-faceted problem, due consideration and importance should be given to the collaborative efforts of the health authorities dealing with human health, animal health, food, and the environment.

\section{Antibiotics for therapeutic and prophylactic use}

Antibiotics can generally be used for therapeutic purposes by administering high doses for a relatively shorter period to individual or small groups of animals or for prophylactic purposes, where animals are exposed to moderate doses for a relatively longer duration (Marshall and Levy, 2011). In case of livestock production and management, use of antibiotics or antimicrobial agents is inevitable as they are not only crucial for treatment of diseases, prevention of diseases, modification of physiological function, promoting growth and production but also for ensuring food safety point of view (Falowo and Festus, 2019). Antibiotics are known to inhibit DNA synthesis (sulfa drugs e.g. sulfamethoxazole trimethoprim, and quinolones e.g. ciprofloxacin, norfloxacin and levofloxacin), RNA and protein synthesis (aminoglycosides, tetracyclines, chloramphenicols), target folic acid metabolism (trimethoprim, sulphonamides), or disrupt cell membrane and cell wall synthesis of microorganisms ( $\beta$-lactams e.g. penicillins, ampicillin, cloxacillin and 
amoxicillin) responsible for dissemination of infections (Velicer et al., 1999; Kohanski et al., 2010; Diarra et al., 2014). In veterinary practice, $\beta$-lactams, tetracyclines, chloramphenicols, macrolides, lincosamide, sulphonamides, nitrofuranes, trimethoprim, polymyxins and quinolones are used (Cháfer-Pericás et al., 2010) for controlling as well as monitoring the important infections such as Salmonella, Leptospira, Campylobacter fetus, Streptococcus suis, Escherichia coli, Enterecoccus (Markey et al., 2013).

\section{Antibiotics for growth promotion}

In 1940s, the growth-promoting effect of antibiotics or antimicrobial agents was detected when improvement of growth in animals was observed by feeding dried mycelia of Streptomyces aureofaciens containing chlortetracycline residues (Castanon, 2007) and it became common practice within few years. As per the National Office of Animal Health (NOAH, 2019), antibiotics or any antimicrobial growth promoters are often used to "help growing animals digest their food more efficiently, get maximum benefit from it and allow them to develop into strong and healthy individuals". Although the main mechanism of action is not clear, it may be related to interactions between the antibiotics and the gut microbiota (Dibner and Richard, 2005). It is believed that these antibiotics act by suppressing the sensitive populations of intestinal microbiota to reduce the loss of net energy from microbial fermentation and divert it to the growth of animals. Moreover, they may facilitate improved nutrient absorption by thinning of intestinal barriers, minimizing toxins production by intestinal bacteria, and reducing incidences of subclinical disease incidences (Butaye et al.,
2003). Tetracyclines, chloramphenicol, and sub-therapeutic doses of procaine penicillin supplemented rations or feeds were extensively used to promote the growth and egg production in poultry (Marshall and Levy, 2011; Kabir et al., 2004).

\section{Antibiotic residues in meat products}

Residues are the active ingredients of the metabolites that remain in meat or any other foodstuff for the animal through which the medicinal products in question have been administered (EC,2002). The access of antibiotics into meat products including milk and fish usually come from its use for different purposes while controlling/ preventing diseases. Sometimes prolonged use in low doses result into the transfer of antibiotics into the products in a very larger form. It has been reported that about 90 percent of antibiotics used in various food animals including poultry are at subtherapeutic concentration (Jayalakshmi et $a l ., 2017)$ and out of that $70 \%$ is for the purpose of diseases prevention and $30 \%$ is for growth promotion. Antibiotics generally get eliminated from the body rapidly and disappear from blood and tissue within few days (Tadesse and Tadesse, 2017). However, indirect contamination of antibiotics through feeds along with contamination of feed with faecal recycling is also a very common incidence and usually through this route it enters into the body of the untreated animals also (Darwish et al., 2013). The contamination of the watercourses particularly the use of antibiotics in fish farming can also be a potent source imparting residues to the animal products through the cycle of soil, plant, water and the animal body (Bacanlý and $\mathrm{Ba}^{\circ}$ aran, 2019). Table 1 shows the presence of different antibiotics in the animal products. 
Table 1. Antibiotic residues in different animal products

\begin{tabular}{|c|c|c|c|c|}
\hline Antibiotic & Instrumentation & Sample & $\begin{array}{l}\text { Residue level } \\
\text { (ppb) }\end{array}$ & Reference \\
\hline \multirow[t]{8}{*}{ Ciprofloxacin } & \multirow[t]{2}{*}{ ELISA } & Chicken muscle & $89.60-175.9$ & \multirow{8}{*}{ Ramatla et al., 2017} \\
\hline & & Chicken liver & $\frac{152.20-289.10}{}$ & \\
\hline & \multirow[t]{3}{*}{ ELISA } & Cattle- muscle & $89.60-146.10$ & \\
\hline & & Cattle- liver & $145.20-316.50$ & \\
\hline & & Cattle- kidney & $98.20-197.70$ & \\
\hline & \multirow[t]{3}{*}{ ELISA } & Pig-muscle & $42.60-95.80$ & \\
\hline & & Pig-liver & $220.00-355.60$ & \\
\hline & & Pig-kidney & $72.50-140.20$ & \\
\hline Quinolone & ELISA & Chicken & 30.81 & Kim et al., 2013 \\
\hline \multicolumn{2}{|l|}{ Enrofloxacin } & Chicken-liver & $10-10690$ & Sultan 2014 \\
\hline \multirow{10}{*}{ Tetracycline } & \multirow[t]{2}{*}{ ELISA } & Cattle- liver & $30-3610$ & \multirow{4}{*}{ Ramatla et al., 2017} \\
\hline & & Sheep-liver & $20-1320$ & \\
\hline & \multirow[t]{2}{*}{ HPLC } & Chicken muscle & $44.30-65.20$ & \\
\hline & & Chicken liver & $46.8-220.2$ & \\
\hline & \multirow[t]{6}{*}{ HPLC } & Cattle -tissue & 176.3 & \multirow{6}{*}{ Abbasi et al., 2012} \\
\hline & & Triceps muscle & 176.3 & \\
\hline & & Gluteal muscle & 405.3 & \\
\hline & & Diaphragm & 96.8 & \\
\hline & & Kidney & 672.40 & \\
\hline & & Liver & 651.30 & \\
\hline Oxytetracycline & HPLC & Cured meat & $42-360$ & Senyuva et al., 2000 \\
\hline Chloramphenicol & ELISA & Chicken & $12.64-226.62$ & Yibar et al., 2011 \\
\hline \multirow[t]{5}{*}{ Sulphonamides } & \multirow[t]{2}{*}{ HPLC } & Chicken muscle & $35.2-81.6$ & \multirow[t]{4}{*}{ Ramatla et al., 2017} \\
\hline & & Chicken liver & $20.7-65.9$ & \\
\hline & \multirow[t]{2}{*}{ ELISA } & Pig-liver & $48.20-69.90$ & \\
\hline & & Pig-kidney & $52.80-92.80$ & \\
\hline & HPLC & Chicken- muscle & $0.02-0.8$ & Mehtabuddin et al., 2012 \\
\hline Doxycycline & LC-MS/MS & Chicken- muscle & 847.7 & Jank et al., 2017 \\
\hline \multirow[t]{3}{*}{ Streptomycin } & \multirow[t]{3}{*}{ ELISA } & Chicken -muscle & $98.44-452.90$ & \multirow[t]{3}{*}{ Ramatla et al., 2017} \\
\hline & & Cattle-muscle & $625.90-989.20$ & \\
\hline & & Pig-muscle & $620.30-875.80$ & \\
\hline
\end{tabular}

Such presence of antibiotic residues constantly get the chance and opportunity to get entrance into the human body system and consequently there will be systemic response within the physiological limit of the human body and develop antibiotic resistance and remain recessive along with the immune system. When that very individual get treated for obvious reasons with antibiotics, fails to get the benefits of it 
and succumbed to diseases owing to the reason of antibiotics resistance phenomenon. World Health Organization has given a caution that human society is likely to face a catastrophe by 2050 where the factor of antibiotic resistance would be a giant killer of human lives, no way inferior to any deadly diseases including cancer.

\section{Long-lasting health impact}

The residues from antibiotics in meat and meat products can potentially be transmitted to humans via consumption of contaminated edible tissues and may lead to several pathological implications. Continuous consumption of meat or meat products contaminated with toxic residues induce changes in the biotransformation of endogenous and exogenous compounds resulting in a variety of health problems, particularly endocrine dysfunction, carcinomas and neurological disorders (Muthukumar and Mandal, 2017). Residual $\beta$-lactams, including cephalosporin and penicillin, have been reported to elicit allergic reactions and can cause dermatitis, cutaneous eruptions and anaphylaxis in humans via ingestion of contaminated meat products (Katz and Brady, 2000; Paige et al., 1997). Residual levels of tetracycline have been reported to lead to poor development of foetuses, staining of teeth in young children, gastrointestinal disorders, and pro-inflammatory, cytotoxic, and immuno-pathological effects (Mund et al., 2017). Chronic exposure to oxytetracycline may lead to leucocytosis, lung congestion, toxic granulation of granulocytes and thrombocytopenic purpura (Lawal et al., 2015; Palmieri et al., 2014). Erythromycin has teratogenic effect-increased probability of cardiac malformation and pyloric stenosis was observed in infants (JECFA, 1997; Maheshwari, 2007). Prolonged exposure or repeated use of chloramphenicol has carcinogenic and genotoxic effects most serious effect is aplastic anaemia and generally fatal in nature (Payne et al., 1999). Persistence of sulphamethazine and furazolidone residues in humans is known to pose immuno-pathological effects (such as autoimmunity, carcinogenicity). Ampicillin may cause allergic reactions, asthmatic attack, exfoliative dermatitis, anaemia, thrombocytopenia, thrombocytopenic purpura, eosinophilia, leukopenia and agranulocytosis (Köklü et al., 2003). Streptomycin has shown to have adverse effects on vestibular mechanisms in the inner ear leading to loss of balance, hypersensitivity, skin rashes and induced fever. It also exhibited neurotoxicity in newborn animals (Katz and Brady, 2000).

In order to control antibiotic residues, the steps should be initiated in the form of using alternatives to antibiotics, reduction in unnecessary use and also reduction in prophylactic use of antibiotics. This will help to minimize the entry of antibiotics into the animal body. Besides, residual control strategies should be initiated with two-step approaches-detection of residues with precision and confirmation. The whole procedure should have a synergistic approach involving all the stakeholders including government, producers, veterinarians, and other interested organizations even without depending solely on government agencies. All the possible ways of contamination of antibiotics should be monitored constantly and thereby a good 
amount of antibiotic could be blocked for getting entry into animal production system. In relation to meat products, cooking and freezing procedures are important to inactivate the antibiotic residues even heating also having effect on inactivation of antibiotics (Darwish et al., 2013). Many workers have reported that some antibiotics such as beta-lactamase, quinolones, sulphonamides, tetracycline, etc are temperature-dependent and prolonged heating time can reduce the antibiotic residues (Tian et al., 2017). Some other methods like using activated charcoal, resin, and $U V$ radiation might have beneficial effect on antibiotic activation (Nisha, 2008). Besides, the early, easy and economic field tests for detection of antibiotic residues in meat and meat products would be helpful to control the menace of antibiotic resistance.

\section{Antimicrobial resistance}

Antimicrobial resistance (AMR) means naturally susceptible bacteria acquire ways to withstand the effects of drugs and not being affected by it. The U.S. Centers for Disease Control and Prevention has described AMR as "one of the world's most pressing health problems". Long term overexposure to antimicrobials or its repeated use in humans and food animals is the single most causative factor responsible for increased antimicrobial resistance. Whereas other factors that influence the development of antibiotic resistance include concentration of drug, duration of exposure, organism type, antimicrobial type and immune status of host (WHO, 1997). The antibiotic resistance can be of two types:

1. Intrinsic resistance, which occurs when the bacterial species are able to innately resist the activity of an antibacterial agent - either the microorganisms naturally do not possess target sites for the drugs or they naturally have low permeability to those drugs because of the differences in the chemical nature of microbial membrane structures and of the drug to restrict its entry for initiating action (Wise, 2002; Yoneyama and Katsumata, 2006).

2. Acquired or active resistance, whereby a naturally susceptible microorganism acquires ways of not being affected by the drug. This is the most important mechanism of antimicrobial resistance, which may occur due to following reasons (Fluit et al., 2001; Langton et al., 2005; Yoneyama and Katsumata, 2006; Fred and Tenover, 2006):

- presence of an enzyme that degrades or inactivates the antimicrobial agent

- a mutation in the antimicrobial agent's target, which reduces the binding of the antimicrobial agent

- post-transcriptional or post-translational modification of the antimicrobial agent's target, which reduces binding of the antimicrobial agent

- reduced uptake of the antimicrobial agent, or acquiring efflux pumps that will extrude the drugs

- horizontal transfer of resistance genes between strains and species by transformation, transduction or conjugation.

In Streptococcus, Meningococcus and other related microorganisms, antibiotic resistance may occur via DNA transformation. Horizontal gene transfer has been observed frequently in Acinetobacter sp., whereas gene amplification is responsible for sulphonamide and trimethoprim resistance 
(Davies and Davies, 2010). Among many organisms, antibiotic-resistant Salmonellae, macrolide or fluoroquinolone-resistant Campylobacters, glycopeptide resistant Enterococci and multiply antibiotic-resistant $E$. coli are the most known antibioticresistant strains (Phillips et al., 2004). Resistant Salmonella and Campylobacter species are commonly found in animal products and pose significant risks to human health, especially in India. Salmonella strain, DT-104, and Campylobacter jejuni are resistant to multiple classes of antibiotics (ampicillin, cephalothin, sulfamethoxazoletrimethoprim), making it very difficult to treat the infection (van den Bogaard and Stobberingh, 2000; Siddiqui et al., 2015). Again it has been reported that avian $E$. coli strains showed significantly higher resistance to trimethoprimsulfamethoxazole and fluoroquinolones, moreover, these antibiotics were also suggested to lead to cross-resistance in human enteric pathogens (Blanco et al., 1997). Ciprofloxacin resistant Salmonella enterica serovar Typhi and ciprofloxacin resistance among Salmonella species are on the rise in India, mostly sourced from poultry (Kumar et al., 2012). In supermarkets, Campylobacter jejuni infected poultry meat has been found, which upon consumption may lead to Campylobacteriosis (Luber et al., 2003; Chuma et al., 2004). Additionally, the occurrence of multidrug-resistant (streptomycin-, ampicillin-, kanamycin-, neomycin-, tetracycline-, erythromycin-, cefotaxime-, bacitracin- and spectinomycin -resistant) Salmonella serovars in chicken meat are of major concern due to their potential transferability to humans via the consumption of meat (Shah and Korejo, 2012). In a recently concluded study on prevalence of antibiotic residues and antibiotic resistance in isolates of chicken meat in Korea, Lee et al. (2018) reported that total rate of detection of antibiotic (residues of 10 out of 17 were found in chicken meat) residues in chicken meat was $45 \%$ (26 out of 58 ) but none crossed the maximum residue level (MRLs). They also reported that among $51 \mathrm{E}$. coli strains isolated from total 58 chicken meat samples, showed the highest resistance to ampicillin $(75 \%)$, followed by tetracycline (69\%), ciprofloxacin $(65 \%)$, trimethoprim/ sulfamethoxazole $(41 \%)$, ceftiofur $(22 \%)$ and amoxicillin/clavulanic acid (12\%).

The New Delhi metallo- $\beta$-lactamase- 1 (NDM-1) gene confers broad resistance to most antibiotics and can be transferred to a wide variety of bacterial species (Deshpande et al., 2010). NDM-1 has been found around the world, including major cities in India (Ganguly, 2011). Carbapenems are considered to be the most reliable 'last-resort' antibiotics, often used to treat infections that are resistant to all other known agents. India has the highest incidence of carbapenemresistant $K$. pneumoniae of nearly anywhere in the world (CDDEP, 2015). Gramnegative bacteria carry extended-spectrum beta-lactamase enzymes (ESBLs), which can confer high levels of resistance to some of the most commonly prescribed antibiotics. ESBL is increasingly found in Escherichia coli and Klebsiella pneumoniae isolates worldwide, especially in Asia - over 80 percent of $E$. coli isolates in India are ESBL producers (CDDEP, 2015). A survey of backyard layers in West Bengal was 
conducted to isolate antibiotic-resistant Salmonella from cloacal swabs, feed samples, drinking water samples and eggs. The isolates were found to be resistant to chloramphenicol, ciprofloxacin, gentamicin, levofloxacin, norfloxacin and oxytetracycline, though none were ESBL producing (Samanta et al., 2014). Out of 1215 samples collected at 154 different farms in Southern India, 21 were positive for nontyphoidal Salmonella. Sixteen were classified as S. Typhimurium and 5 as S. Enteritidis, both strains were highly associated with human disease. All 21 isolates were resistant to oxytetracycline, a routine poultry feed additive (Saravanan et al., 2015).

\section{Global and national policies - responding to antimicrobial resistance}

The World Health Organization (WHO), Food and Agricultural Organization (FAO), World Organisation for Animal Health (OIE), European Union (EU), European Centre for Disease Prevention and Control (ECDC), and governments across the globe are committed to develop guidelines and policies to regulate and to monitor the use of antibiotics in food animals and subsequent development of antibiotic resistance (Walia et al., 2019). The WHO has endorsed the 'One Health approach' to address this problem globally through an alliance between WHO, FAO and OIE referred as 'Tripartite Alliance' (WHO, 2015). In partnership with its tripartite partners, the WHO published the 'Global Action Plan (GAP) on antimicrobial resistance' in 2015 (WHO, 2015). The GAP focuses on the set of strategies including improving sanitation, cleanliness, hygiene and proper awareness about AMR, strengthening surveillance, promoting research, reducing infection incidence and optimizing the use of antibiotics along with improved interventions (Walia et al., 2019). It further provides strategic guidance to minimize the risk of animal food safety with associated hazards and zoonosis (WHO, 2015). The WHO has also ranked antibiotics or antimicrobials as per importance to human medicine, with the aim to restrict the use of antibiotics or antimicrobials in foodproducing animals and specially reserve certain classes of drugs for human use (Collignon et al., 2016). The FAO has also launched its 'AMR Strategy' to implement the WHO's GAP in the animal food and agricultural sectors (FAO, 2016). The OIE has stressed on the implementation of veterinary legislation and regulations approving judicial use of 'Veterinary Critically Important Antimicrobial Agents, Veterinary Highly Important Antimicrobial Agents and Veterinary Important Antimicrobial Agents' (OIE 2015, 2016).

As one of the countries most affected by AMR, India is now taking appropriate steps to address the growing problem of drug resistance by judicial use of antibiotics both in the case of humans and animals. In 2007, the Bureau of Indian Standards of Poultry Feed recommended stopping the use of antimicrobials or antibiotics with systemic action as antibiotic growth promoters in a feed (BIS, 2007). There has been legislation recently on antibiotic residues, toxins and other contaminants in different food products including meat and meat products (Table 2) promulgated by Food Safety and Standard Authority of India in December 2018 (FSSAI, 2018).

In 2012, the Ministry of Health and Family Welfare released the National Policy for Containment of Antimicrobial Resistance 
under the aegis of the National Centre for Disease Control (NCDC). The objectives of this program were to - establish a laboratory-based AMR surveillance system of 30 network laboratories; generate quality data on AMR for microbial pathogens of public health as well as zoonotic importance; strengthen the ways for infection control guidelines and practices, and promote rational use of antibiotics; and generate awareness about the use of antibiotics in both healthcare providers and in the community (DGHS, 2011).

The 2012 Chennai Declaration-A Roadmap to Tackle the Challenge of Antimicrobial Resistance, was developed at the Joint Meeting of Medical Societies in India, organized as a pre-conference symposium of the 2nd Annual Conference of the Clinical Infectious Disease Society (CIDSCON) on 24th August, 2012. The following needs, as per CIDSCON, were outlined (Ghafur et al., 2013) -

1) to evaluate the extent of antibiotic usage in the veterinary practice and the indications of use (prophylaxis, treatment, or growth promoter)

2) to regulate antibiotic usage in the veterinary practice

3 ) to ascertain and monitor the prevalence of resistant bacteria, especially important zoonotic food-borne bacteria in animals and food of animal origin to quantify the rate of transfer of medically relevant resistance genes and resistant bacteria from animals to humans

4) to regulate the monitoring of residues of antibiotics in the food of animal origin and study the role of antibiotic residues in food towards development of resistance
5) to formulate/implement proper regulations and protocol for the observance of withholding or withdrawal periods between the use of antibiotics and food animal slaughter or milking to avoid residues of antibiotics in meat and milk.

In January 2012, the Central Drugs Standard Control Organization (CDSCO) introduced a new norm that specifies the withdrawal period, or the time frame for poultry, livestock and marine products to be kept off antimicrobials or antibiotics before they enter the food chain. According to the new norms that specify the withdrawal period, milk and egg products will have to be off antibiotics for seven days before they can enter the food chain. In case of poultry and food-producing animal, the corresponding period will be 28 days.

In 2014, the Department of Animal Husbandry, Dairying and Fisheries (DAHDF) issued a circular to its officials across India, advising them to use antibiotics judiciously for treatment of all foodproducing animals and animal feeding. It also advised that the use of all antibiotics and hormones in animal feed should be stopped immediately.

In 2015, the Food Safety and Standards Authority of India (FAAAI) issued guidelines to limit the use of antibiotics as well as veterinary drugs in meat and meat products. It is proposed that feed for meatproducing animals or birds should not include meat, blood meal and bone tissues except milk and milk products. The FSSAI has also suggested different slaughterhouse for poultry and livestock animals and there 
Table 2. Antibiotics and veterinary drugs and their tolerance limit in different edible animal tissues, fat, and eggs

\begin{tabular}{|c|c|c|}
\hline Sl. no. Antibiotics and veterinary drugs & Food & $\begin{array}{l}\text { Tolerance } \\
\text { limit }(\mathrm{mg} / \mathrm{kg})\end{array}$ \\
\hline $\begin{array}{l}\text { Ampicillin, Cloxacillin, Salinomycicin, Sulphadiazine, } \\
\text { Sulphathiazole Sodium, Trimethoprim, Sulfanilamide, } \\
\text { Sulfaguanidine, Sulphathiazole Sodium, Trimethoprim, } \\
\text { Sulfanilamide, Sulfaguanidine. Zinc Bacitracin (min } \\
60 \mathrm{IU} / \mathrm{mg} \text { dried subs), Amprolium, Cephapirine, } \\
\text { Clopidol, Enrofloxacin, Ethopabate, Flavophospholipol } \\
\text { (Flavomycin), Sulphaquinoxaline, Amitraz, Aspirin, } \\
\text { Buqarvaquone, Buserelin, Butafosfane, Butaphosphan, } \\
\text { Calcium Magnesium Borogluconate, } \\
\text { Carboprosttromethamine, Chloral hydrate, } \\
\text { Closprostenol Sodium, Ketaminehydrochloride, } \\
\text { Kaolin, Ivermectin, Haloxon, Halofuginone, Flunixin, } \\
\text { Meglumine, Semduramycin, Rafoxanide, Prosolvin, } \\
\text { Propofol, Promazine Hydrochloride, Proligestone, } \\
\text { Praziquantel, Pentobarbitone, Parbendazole, } \\
\text { Oxyclozanide, Meloxicam, Niclosamide, } \\
\text { Oxybendazole, Praziquantel, Proligestone, Prosolvin, } \\
\text { Rafoxanide, Sulpha Chloropyrazine Sodium, Suramin }\end{array}$ & $\begin{array}{l}\text { All edible } \\
\text { animal } \\
\text { tissues } \\
\text { Fats } \\
\text { derived } \\
\text { from } \\
\text { animal } \\
\text { tissues } \\
\text { Milk }\end{array}$ & 0.01 \\
\hline
\end{tabular}

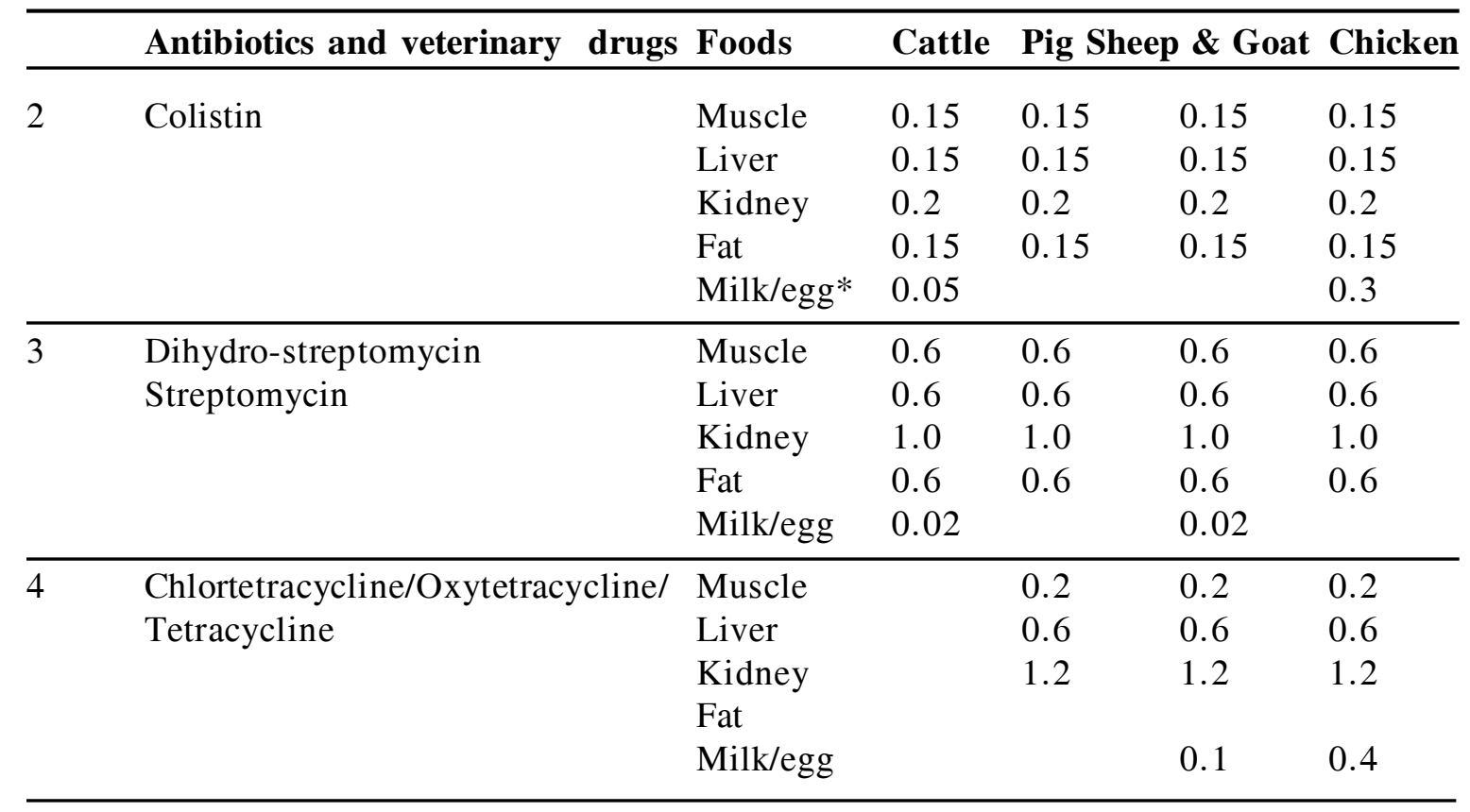


Cont. Table 2.

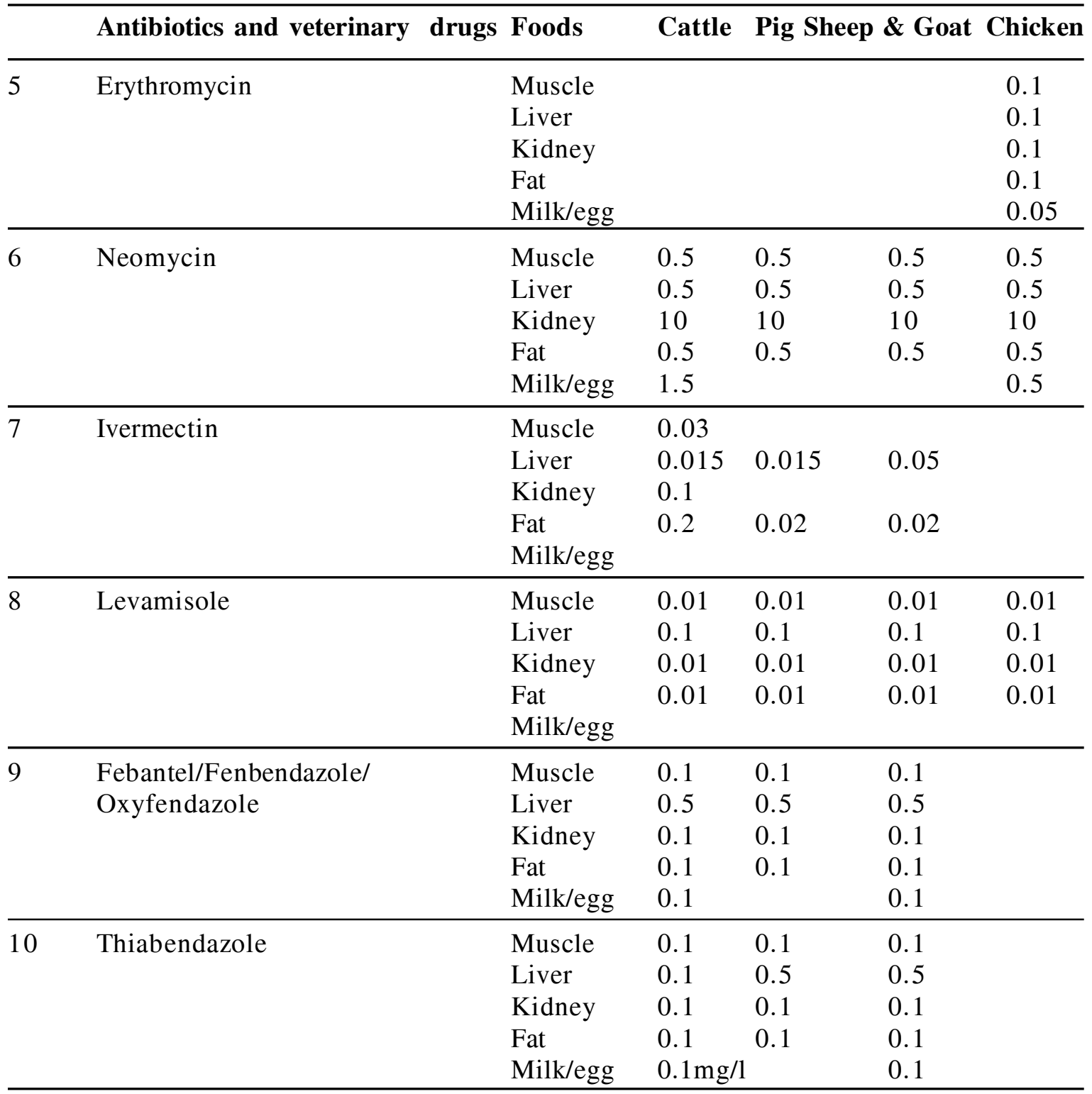

Note: Antibiotics and veterinary drugs such as nitrofurans including-furaltadone, furazolidone, nitrofurnatoin, nitrofurazone, chloramphenicol, sulphamethoxazole, Aristolochia spp and preparations thereof, chloroform, chloropromazine, colchicine, dapsone, dimetridazole, metronidazole, ronidazole, ipronidazole and other nitromidazoles, clenbuterol, diethylstibestrol, glycopeptides, stilbenes and other steroids, crystal violet, malachite green, carbadox, are not permitted to be used at any stage of processing of meat and meat products, poultry and eggs, seafoods including shrimps, prawns or any variety of fish and fishery products. The Extraneous Maximum Residue Limit of $0.001 \mathrm{mg} / \mathrm{kg}$ will be applicable except for chloramphenicol for which it shall be $0.0003 \mathrm{mg} / \mathrm{kg}(0.3 \mathrm{ug} / \mathrm{kg})$ * egg for chicken only. Source- FSSAI website 
Recently, the National Action Plan on AMR (2017-2021) has identified following strategic priorities under NAP-AMR in India:

$\overline{\text { Strategic priority } 1}$ Improve awareness and understanding of AMR through effective communication, education, and training

Strategic priority 2 Strengthen knowledge and evidence through surveillance

Strategic priority 3 Reduce the incidence of infection through effective infection prevention and control

Strategic priority 4 Optimize the use of antimicrobial agents in health, animals, and food

Strategic priority 5 Promote investments for AMR activities, research, and innovations

Strategic priority 6 Strengthen India's leadership on AMR by International, National and State level collaborations

should be a slaughter of only those animals that are allowed as per the Food Safety and Standards (Food Product Standards and Food Additives) regulations, 2011 (FSSAI, 2015). The FSSAI in November 2017 has invited comments from all stakeholders and the general public to set a maximum tolerance limit of antibiotics and veterinary drugs in all edible tissues from food-producing animals. The detail of the above limits has been illustrated in Table 2 for reference purposes.

he NAP-AMR further promotes the One Health perspective of integrating human and animal health sectors.

In 2017, the Indian Council of Medical Research (ICMR) in collaboration with the Indian Council of Agriculture Research (ICAR) has initiated a project to develop standard operating procedures for antimicrobial susceptibility testing for veterinary microbiology laboratories and identify available capacities and the gap areas. The project envisages developing capacity in AMR in the veterinary sector for providing important linkages with human sector (Walia et al., 2019). In June 2017, the ICMR organized a meeting with all the relevant stakeholders to discuss the possibility of reserving a few classes of drugs for human use. Following observations were made from the above meeting:

- 'Critically important' or 'last line' antibiotics for humans (WHO, 2017) vizpolymyxins, glycopeptides, fluoroquinolones and fourth- and fifth-generation cephalosporins should not be used for treatment in foodproducing animals.

- Penicillin, tetracyclines, cephalosporins, quinolones, sulphonamides, and aminoglycosides should be exclusively used for the treatment of animals. Glycopeptides and carbapenems are used in pets.

- Diagnostic methods for the detection of AMR in animals need to be standardized and uniformity should be maintained throughout all the veterinary laboratories across the country.

- Research should be carried out to study the spread of AMR between animals, humans and fisheries.

- Action points were suggested for urgent implementation of antibiotics used in food animals with the help of DAHDF, ICAR and Drug Controller General of India (DCGI). 


\section{Recommendations}

In order to conserve the effectiveness of antimicrobials in human and animals, the following recommendations can be made:

Educate farmers, veterinarians, and consumers on the dangers of AMR

There is still a lack of awareness about AMR among producers and consumers. Education and raising awareness through extension education conducted by veterinary and agricultural universities or through regular and social media can play a role in reducing the use of antimicrobials or antibiotics in animals and demand for antibiotic-free products. Phase-out the sub-therapeutic use of
antibiotics in animals

Sub-therapeutic use of antibiotics should be phased out gradually over time to avoid any unintended negative effects on animal health. The total use of antimicrobials or antibiotics along with total production costs should be monitored. This approach has great potential to reduce overall antibiotic or antimicrobial use and resistance.

Nationwide surveillance and monitoring system to track veterinary antibiotic use, resistance, and residues

Tracking veterinary antibiotic use, residues, and resistance has not been done systematically in India. To fill this knowledge gap, a surveillance system should be initiated, collecting qualitative and quantitative information over time. Scientists from veterinary universities, ICAR, representative from ministry and surveillance experts should monitor the surveillance system.

Developing new antibiotics and diagnostic tests As antibiotic or antimicrobial resistance develops as part of a natural evolution process, it can be significantly reduced but cannot be stopped completely. Therefore, the development of new antimicrobials or antibiotics will always be essential to keep up with resistant bacteria as well as new diagnostic tests to track antibiotic resistance.

\section{Conclusion}

The Indian National Action Plan for AMR is a well-articulated comprehensive plan, which addresses all the important regulatory issues and appropriate guidelines related to antibiotic or antimicrobial use as per the "One Health Approach." However, a separate funding allocation with strategic coordination between central and state governments is needed for its effective implementation and a big cohesive workplan and push is needed by all stakeholders. A multisectoral and multidisciplinary approach with combined efforts and supervision with sound monitoring system is the need of the hour. Government and private sectors, veterinarians along with food industries especially foods of animal origin related to food production and food chain, and pharmaceutical industries have a crucial role to design the strategies and tackle the issues of AMR to halt its progress where antibiotic residues in the meat and meat products especially having big role. Therefore, in the comprehensive program to tackle AMR, this aspect of genesis of antibiotic resistance through antibiotic residues within muscles, requires a thorough understanding and must be included in the study of tackling AMR. Once implemented, proper surveillance by the authorities in monitoring and evaluation of all the objectives including the assessing of antibiotic residue levels with minimization of possible antibiotic contamination in animal food chain would finally give results in lower the resistance burden in humans and animals particularly in reference to India. 


\section{REFERENCES}

Abbasi MM, Nemati M, Babaei H, Ansarin M and Nourdadgar AOS, 2012. Solid-Phase extraction and simultaneous determination of tetracycline residues in edible cattle tissues using an HPLC-FL method. Iran J Pharm Res, 11(3): 781-787

Bacanlý $\mathrm{M}$ and $\mathrm{Ba}^{\circ}$ aran $\mathrm{N}, 2019$. Importance of antibiotic residues in animal food. Food Chem Toxicol, 125: 462-466

BIS (Bureau of Indian Standards), 2007. Indian Standard, Poultry Feeds - Specifications. $5^{\text {th }}$ Revision, IS 1374, New Delhi

Blanco JE, Blanco M, Mora A and Blanco J, 1997. Prevalence of bacterial resistance to quinolones and other antimicrobials among avian Escherichia Coli strains isolated from septicemic and healthy chickens in Spain. J Clin Microbiol, 35(8): 2184-2185

Butaye P, Devriese LA and Haesebrouck F, 2003. Antimicrobial growth promoters used in animal feed: Effects of less well-known antibiotics on gram-positive bacteria. Clin Microbiol Rev, 16(2): 175-188

Castanon J, 2007. History of the use of antibiotic as growth promoters in European poultry feeds. Poult Sci, 86: 2466-2471

CDDEP (Center for Disease Dynamics, Economics \& Policy), 2015. State of the World's antibiotics. Available in https:// www.cddep.org/wp-content/uploads/2017/ 06/swa_executive_summary_edits_2016.pdf [10 Sep, 2019]

Cháfer-Pericás C, Maquieira A and Puchades R, 2010. Fast screening methods to detect antibiotic residues in food samples. TRACTrend Anal Chem, 29: 1038-1049

Chuma T, Maeda T, Niwa H and Okamoto K, 2004.
Acquisition of quinolone resistance and point mutation of the gyr A gene in Campylobacter jejuni isolated from broilers and in vitroinduced resistant strains. J Vet Med Sci, 66: $155-160$

Collignon PJ, Conly JM, Andremont A, McEwen SA and Aidara-Kane A, 2016. World Health Organization Advisory Group. Bogotá Meeting on Integrated Surveillance of Antimicrobial Resistance (WHO-AGISAR) World Health Organization ranking of antimicrobials according to their importance in human medicine: A critical step for developing risk management strategies to control antimicrobial resistance from food animal production. Clin Infect Dis, 63: 1087-1093

Darwish WS, Eldaly EA, El-Abbasy MT, Ikenaka Y, Nakayama S et al., 2013. Antibiotic residues in food: The African scenario. Jpn J Vet Res, 61: S13-S22

Davies J and Davies D, 2010. Origins and evolution of antibiotic resistance. Microbiol Mol Biol Rev, 74: 417-433

Deshpande P, Rodrigues C, Shetty A, Farhad K, Hedge A et al., 2010. New Delhi metallo- $\beta$ lactamase (NDM-1) in Enterobacteriaceae: Treatment options with carbapenems compromised. J Assoc Physic India, 58: 147-149

DGHS (Directorate General of Health Services), 2011. National policy for containment of antimicrobial resistance. New Delhi. Available in https://mohfw.gov.in/sites/ default/files/3203490350abpolicy\% 20\%281\%29.pdf [8 Sep, 2019]

Diarra MS and Malouin F, 2014. Antibiotics in Canadian poultry productions and anticipated alternatives. Front Microbiol, 5: 1-15

Dibner JJ and Richard JD, 2005. Antibiotic growth 
promoters in agriculture: history and mode of action. Poult Sci, 84: 634-643

EC, European Commission, 2002. Commission Decision of 12 August 2002 implementing Council Directive 96/23/EC concerning the performance of analytical methods and the interpretation of results. J Eur Communi, 221: 8-36

Falowo AB and Festus AO, 2019. Veterinary Drug Residues in Meat and Meat Products: Occurrence, Detection and Implications. Publisher: IntechOpen, DOI: 10.5772/ intechopen. 83616

FAO (Food and Agriculture Organization), 2016. The FAO Action Plan on Antimicrobial Resistance 2016-2020. Supporting the food and agriculture sectors in implementing the global action plan on antimicrobial resistance to minimize the impact of antimicrobial resistance, Rome

FSSAI (Food Safety and Standard Authority of India), 2018. Food safety and standards (contaminants, toxins and residues), Accessed from www.fssai.gov.in (28 ${ }^{\text {th }}$ October 2019)

Fluit AC, Visser MR and Schmitz FJ, 2001. Molecular detection of antimicrobial resistance. ClinMicrobiol Rev, 14:836-871

Fred C and Tenover FC, 2006. Mechanisms of antimicrobial resistance in bacteria. Am $\mathbf{J}$ Med, 119 (6): S3-S10

FSSAI (Food Safety and Standards Authority of India), 2015. Comments with regard to placing of meat and poultry products on the Indian market. New Delhi: Controller of Publications, Ministry of Health and Family Welfare, Government of India. Available in http:// old.fssai.gov.in/Portals/0/Pdf/Draft/_Meat_ Poultry_Comments.pdf. [10 Sep, 2019]

Ganguly NK, 2011. Situation Analysis: Antibiotic use and resistance in India. New Delhi: Global Antibiotic Resistance Partnership. Available in https://cddep.org/wp-content/uploads/ 2017/06/india-report-web_8. pdf [8 Sep, 2019]

Ghafur A1, Mathai D, Muruganathan A, Jayalal JA, Kant R et al., 2013. The Chennai Declaration: a roadmap to tackle the challenge of antimicrobial resistance. Indian J Cancer, 50(1): 71-73

Government of India (GOI), 2017. National Action Plan on Antimicrobial Resistance (NAPAMR) 2017 - 2021. [accessed on Ocotober 22, 2019]. Available from: http:// www.searo.who.int/india/topics/ antimicrobial_resistance/nap_amr.pdf.

Jank L, Martins MT, Arsand JB, Motta TMC, Feij TC et al., 2017. Liquid chromatographytandemmass spectrometry multiclass method for 46 antibioticsresidues in milk and meat: Development and validation. Food Anal Methods, 10: 2152-2164

Jayalakshmi K, Paramasivam M, Sasikala M, Tamilam TV and Sumithra A, 2017. Review on antibiotic residues in animal productsand its impact on environments and human health. J Entomol Zool Stud, 5(3): 1446-1451

JECFA (Joint Expert Committee on Food Additives), 1997. Toxicological evaluation of certain veterinary drug residues in food, WHO Food Additives Ser, 39

Kabir J, Umoh VJ, Audu-okoh E, Umoh JU and Kwaga JKP, 2004. Veterinary drug use in poultry farms and determination of antimicrobial drug residues in commercial eggs and slaughtered chicken in Kaduna State, Nigeria. Food Control, 15: 99-105

Katz SE and Brady MS, 2000. Antibiotic residues in food and their significance. Food Biotechnol, 14: 147-171 
Kim DP, Degand G, Douny C, Pierret G, Delahaut P et al., 2013. Preliminary evaluation of antimicrobial residuelevels in marketed pork and chicken meat in the red riverdelta region of Vietnam. Food Public Health, 3(6): 267276

Kohanski MA, Dwyer DJ and Collins JJ, 2010. How antibiotics kill bacteria: From targets to networks. Nat Rev Microbiol, 8(6): 423-435

Köklü S, Yüksel O, Filik L, Üsküdar O, Altundað K et al., 2003. Recurrent cholestasis due to ampicillin. Ann Pharmacother, 37(3): 395397

Kumar T, Mahajan NK and Rakha NK, 2012. Isolation and prevalence of Salmonella serovars from poultry in different parts of Haryana, India. Indian J Anim Sci, 82 (6): 557-560

Langton KP, Henderson PJ and Herbert RB, 2005. Antibiotic resistance: multidrug efflux proteins, a common transport mechanism. Nat Prod Rep, 22: 439-451

Lawal JR, Jajere SM, Geidam YA, Bello AM, Wakil $\mathrm{Y}$ et al., 2015. Antibiotic residues in edible poultry tissues and products in Nigeria: A potential public health hazard. Int J Anim Vet Adv, 7(3): 55-61

Laxminarayan R, Duse A, Wattal C, Zaidi AK, Wertheim HF et al., 2013. Antibiotic resistance: the need for global solutions. Lancet Infect Dis, 13: 1057-1098

Laxminarayan R, Matsoso P, Pant S, Brower C, Rottingen JA et al., 2016. Access to effective antimicrobials: A worldwide challenge. Lancet, 387: 168-175

Lee H, Cho S, Shin D and Kang H, 2018. prevalence of antibiotic residues and antibiotic resistance in isolates of chicken meat in Korea. Korean J Food Sci Anim Resour, 38(5): 1055-1063
Luber P, Wagner J, Hahn H and Bartelt E, 2003. Antimicrobial resistance in Campylobacter jejuni and Campylobacter coli strains isolated in 1991 and 2001-2002 from poultry and humans in Berlin, Germany. Antimicrob Agents Chemother, 47: 3825-3830

Maheshwari N, 2007. Are young infants treated with erythromycin at risk for developing hypertrophic pyloric stenosis. Arch Dis Child, 92(3): 271-273

Markey B, Leonard F, Archambault M, Cullinane $A$ and Maguire D, 2013. Clinical Veterinary Microbiology. Elsevier Health Sciences, US

Marshall BM and Levy SB, 2011. Food animals and antimicrobials: Impacts on human health. Clin Microbiol Rev, 24(4): 718-733

Mehtabuddin A, Mian A, Ahmad T, Nadeem S, Tanveer ZI et al., 2012. Sulfonamide residues determination in commercial poultry meat and eggs. J Anim Plant Sci, 22: 473-478

Mund M, Khan U, Tahir U, Mustafa B and Fayyaz A, 2017 Antimicrobial drug residues in poultry products and implications on public health: A review. Intl J Food Properties, 20 (7): 1433-1446

Muthukumar M and Mandal PK, 2017. Concerns and consequences of industrial livestock and meat production. J Meat Sci, 12(2): 1-9

National Office of Animal Health (NOAH). Antibiotics for animals. http:// www.noah.co.uk/issues/antibiotics. htm Last accessed 18 October 2019

Nisha A, 2008. Antibiotic residues-a global health hazard. Vet World, 1: 375

OIE (World Organization for Animal Health), 2015. OIE list of antimicrobial agents of veterinary importance. Available in https://www.oie.int/ doc/ged/D9840.PDF [10 Sep, 2019] 
OIE (World Organization for Animal Health), 2016. OIE annual report on the use of antimicrobial agents in animals. Better understanding of the global situation. Available in https:// www.oie.int/fileadmin/Home/eng/ Our_scientific_expertise/docs/pdf/AMR/ Survey_on_monitoring_antimicrobial_ agents_Dec 2016. pdf [10 Sep, 2019]

O’Neill J, 2014. Antimicrobial Resistance: Tackling a crisis for the health and wealth of nations. Review on Antimicrobial Resistance. Available in https://amr-review.org/sites/ default/files/AMR\% 20Review\% 20 Paper $\% 20-\% 20$ Tackling\%2 0a\% 20crisis \%20 for $\% 20$ the $\% 20$ health $\% 20$ and $\% 20$ wealth $\% 20$ of \% 20 nations.pdf. 1 [16 Sep, 2019]

O’Neill J, 2016. Tackling drug-resistant infections globally: final report and recommendations. Review on Antimicrobial Resistance. Available in https://amr-review.org/sites/ default/files/160518Final\%20paper with\%20cover.pdf. [16 Sep, 2019]

Paige JC, Tollefson L and Miller M, 1997. Public health impact on drug residues in animal tissues. Vet Human Toxicol, 9: 1-27

Palmieri MD, Cerbo AD and Laurino C 2014. Antibiotic Treatments in zootechnology and effects induced on the food chain of domestic species and comparatively, the human species. Nutricion Hospitalaria, 29: $1427-$ 1433

Payne MA, Baynes RE, Sundolf SF, Craigmill A, Webb AI et al., 1999. E drugs prohibited from extra label use in food animals. J Am Vet Med Assoc, 215(1): 28-32

Phillips I, Casewell M, Cox T, De Groot B, Friis C et al., 2004. Does the use of antibiotics in food animals pose a risk to human health? A critical review of published data. J Antimicrob Chemother, 53: 28-52
Ramatla T, Ngoma L, Adetunji M and Mwanza M, 2017. Evaluation of antibiotic residues in raw meat using different analytical methods. Antibiotics, 6: 34, doi: 10.3390/ antibiotics6040034

Samanta I, Joardar SN, Das PK, Sar TK, Bandyopadhyay S et al., 2014. Prevalence and antibiotic resistance profiles of Salmonella serotypes isolated from backyard poultry flocks in West Bengal, India. J Appl Poult Res, 23(3): 536-545

Saravanan S, Purushothaman V, Murthy TR, Sukumar K, Srinivasan P et al., 2015. Molecular epidemiology of nontyphoidal Salmonella in poultry and poultry products in India: Implications for human health. Indian J Microbiol, 55(3): 319-326

Senyuva H, Ozden T and Sarica DY, 2000. Highperformance liquid chromatographic determination of oxytetracycline residue in cured meat products. Turk J Chem, 24: 395400

Shah AH and Korejo NA, 2012. Antimicrobial resistance profile of Salmonella Serovars isolated from chicken meat. J Vet Anim Sci, 2: $40-46$

Siddiqui FM, Akram M, Noureen N, Noreen Z and Bokhari H, 2015. Antibiotic susceptibility profiling and virulence potential of Campylobacter jejuni isolates from different sources in Pakistan. Asian Pac J Trop Med, 8(3): 197-202

Sultan IA, 2014. Detection of enrofloxacin in livers oflivestock animals obtained from a slaughterhouse in Mosul City. J Vet Sci Tech, 5(2): $1-3$

Tadesse T and Tadesse T, 2017. Public health impacts of antibiotic residues in foods of animal origin: A review. Public Policy Adm Res, 7: 6-11 
Tian L, Khalil S and Bayen S, 2017. Effect of thermal treatments on the degradation of antibiotic residues in food. Crit Rev Food Sci Nutr, 57: 3760-3770

Van Boeckel T, Brower C, Gilbert M, Grenfell B, Levin $\mathrm{S}$ et al., 2015. Global trends in antimicrobial use in food animals. Proc Natl Acad Sci USA, 112(18): 5649-5654

van den Bogaard AE and Stobberingh EE, 2000. Epidemiology of resistance to antibiotics: links between animals and humans. Int $\mathbf{J}$ Antimicrob Agents, 14: 327-335

Velicer CM, Heckbert S, Johanna W, Lampe RD, Potter JD et al., 1999. A review of the mechanisms of action and resistance of antimicrobial agents. Can Respir J, 6: S20-S22

Walia K, Sharma M, Vijay S and Shome B, 2019. Understanding policy dilemmas around antibiotic use in food animals and amp; offering potential solutions. Ind J Medical Res, 149(2): 107-118

WHO (World Health Organization), 1997. The Medical Impact of the Use of Antimicrobials in Food Animals. Available in https:// apps.who.int/iris/bitstream/handle/10665/ 64439/WHO_EMC_ZOO_97.4.pdf? sequence $=1$ [9 Sep, 2019]

WHO (World Health Organization), 2014. WHO's first global report on antibiotic resistance reveals serious, worldwide threat to public health. Available in http://www.who.int/ mediacentre/news/releases/2014/amr-report/ en/ [10 Sep, 2019]

WHO (World Health Organization), 2015. Global action plan on antimicrobial resistance. Available in http://www.wpro.who.int/entity/ drug_resistance/resources/global_action_ plan_eng.pdf [Nov 14, 2017]

WHO (World Health Organization), 2017. The Selection and Use of Essential Medicines. Report of the WHO Expert Committee on Selection and Use of Essential Medicines, (including the 20th WHO Model List of Essential Medicines and the 6th WHO Model List of Essential Medicines for Children); WHO Technical Report Series 1006, Geneva

Wise R, 2002. Antimicrobial resistance priorities for action. J Antimicrob Chemother, 49: 585-586

Yibar A, Cetinkaya F and Soyutemiz GE, 2011. ELISA screeningand liquid chromatographytandem mass spectrometry confirmation of chloramphenicol residues in chicken muscle, and the validation of a confirmatory method by liquid chromatography-tandem mass spectrometry. Poultry Sci, 90: 2619-2626

Yoneyama H and Katsumata R, 2006. Antibiotic resistance in bacteria and its future for novel antibiotic development. Biosci Biotechnol Biochem, 70: 1060-1075 